\title{
PRACTICAL AND SCIENTIFIC CHALLENGES IN ADAPTING DIGITAL COGNITIVE TESTS IN PROFESSIONAL ENVIRONMENT
}

\author{
Mélany Payoux ${ }^{1,2}$, Lara Abdel Halim ${ }^{1}$, Alexandra Didry ${ }^{2}$, \& Arnaud Trenvouez ${ }^{2}$ \\ ${ }^{1}$ Faculty of psychology, LPPL UPRES EA 4638, University of Nantes (France) \\ ${ }^{2}$ PerformanSe, Nantes (France)
}

\begin{abstract}
Recruiting today is no longer what it used to be. Digital transformation has deeply changed the company, and particularly the recruitment process. The challenges linked to this transformation are two-fold: practical and scientific. Indeed, the world of human resources needs new tools to detect potentials. Research must meet this need by adapting, modernizing and scientifically validating the tools. To predict job performance, cognitive and soft skills, often referred to as "21st century skills", are now central to recruitment, talent development and career management. The objective of our study was to create digital versions of cognitive tests, based on reliable and well-known theoretical foundations. We want to present in detail the conception and construct validity of two of our online tests: the first one inspired by the Stroop effect (Stroop, 1935), the second one based on corsi blocks (Corsi, 1972). We hypothesise that the tests we created are positively correlated to the original ones. 91 participants were interviewed, aged between 18 and 58 (average $=34.57$ years old, $\mathrm{SD}=10.91)$. The proportion of women was $76.6 \%(\mathrm{n}=69)$, compared to $24.4 \%$ of men $(\mathrm{n}=22)$. They all answered the original tests first, face-to-face, and a few months later, the digital ones we had created. We observed positive correlations between the two series of results. These very encouraging results will be clarified and discussed. These two new versions shed light on the candidates' attention and memory abilities that should be enriched during an interview focused on soft skills. In fact, the highest predictability is guaranteed by a method which necessarily combines cognitive evaluations and with other types of assessments, such as personality tests (Güler, Bayrak \& Ocaks, 2019). This is why it is important to continue research efforts on the adaptation of digital cognitive tests in a professional environment.
\end{abstract}

Keywords: Cognitive gaming, recruitment, memory, attention.

\section{Introduction}

Cognitive and soft skills, often referred to as "21st century skills", are considered predictors of job performance. They are, in fact, central to recruitment, talent development and career management. Cognitive assessment is usually carried out by means of cognitive tests, often described in the literature as standardised tools that allow cognitive abilities to be assessed in a "reliable, standardised and objective" way (Ones, Dilchert, Viswesvaran, \& Salgado, 2010). Their use is ideal both for the power of their prediction on certain business outcomes and for their lower cost of application (Schmidt \& Hunter, 1998; Sonnentag, Volmer, \& Spychala, 2008; Salgado, 2017; Schmidt, Oh, \& Shaffer, 2016). As intelligence models have been developed and tested for more than a century, the theoretical foundations of cognitive tests are stronger than those of other selection methods (Schmidt, Oh \& Shaffer, 2016; Salgado, 2017). Nevertheless, the tests recognised in the literature do not have a digital version that is much more adapted to the professional environment and the advances of the 21 st century.

Indeed, the digital transformation has profoundly changed the company, and in particular the recruitment process. Thus, the challenges linked to this transformation are twofold: practical and scientific. On the practical side, the human resources world needs digital tools that assess cognitive abilities and meet scientific criteria for detecting potential. On a scientific level, research must respond to this need from the professional world by adapting, modernising and scientifically validating the tools.

The challenge is significant because there is a paradox between the results of research on the validity of these tools and their use by professionals (Terpstra and Rozell, 1997; Chartier, 2009). This low use of powerful tools for recruiting candidates would be due, in addition to the availability of digital versions, to a lack of access by professionals to precise information on validity (Chartier, 2009). 


\section{Objectives}

The aim of our study is to create digital versions of cognitive tests, based on reliable and well-known theoretical foundations. Only two numerical test creations will be presented here, dealing respectively with the cognitive skills of "memory" and "attention".

\subsection{Memory test}

Working memory abilities are usually assessed by means of span tasks. These span tasks can be verbal (memorising words, numbers) or visuospatial in nature. According to the scientific literature, there is no difference in the results between a verbal and a visuospatial span task (Maquestiaux, 2017).

We chose a visuospatial span test inspired by the Corsi block test (Corsi, 1972). This test is used to assess the immediate non-verbal memory in its visuospatial aspects.

Alloway \& Temple (2007) demonstrated, by adapting the Corsi block test on a computer, the measurement of visuospatial short-term memory. Their results show a good test-retest reliability of 0.83 , thus justifying the psychometric quality.

\subsection{Attention test}

As Dégruel, Enlart, Le Boulaire, and Marsaudon (2011) point out, the hyperconnected work environment in which we evolve requires us to process several similar but also different pieces of information at the same time. This simultaneous processing of information is cognitively costly and directly solicits our attentional capacities. Attention therefore allows us to change tasks or mental strategies to switch from one cognitive operation to another. It can require disengagement from one task to re-engage in another. Finally, attention can shed light on an individual's ability to focus on a stimulus that is relevant to a task and to ignore other irrelevant stimuli presented simultaneously. This cognitive skill thus allows adaptation to new situations. The test we have created is inspired by the Stroop test whose effect was discovered in 1935 by John Ridley Stroop. Our creation aims to go beyond Stroop's original paradigm by evaluating attentional capacity with inhibition and flexibility.

We will call our digital creation of the Corsi blocks "New Corsi" and our digital creation of the Stroop task "New Stroop".

\section{Methods}

\subsection{Sample}

To maximise the diversity of our sample while remaining close to a working population, various acquisition channels were used. Participants were approached at their place of work or school. The interest and objective of the study conducted was explained so that the person could freely choose to participate.

91 people responded to the original tests (age range 18 - 58 years, $\mathrm{M}=34.57$ years, $\mathrm{SD}=10.91$ ). The proportion of women was $76.6 \%(n=69)$, compared to $24.4 \%$ of men $(n=22)$. Unfortunately, we observe an experimental mortality as only 57 people responded to the digital tests. Thus, our final sample on which our statistics are based is $73.7 \%$ female $(n=42)$, against $26.30 \%$ male (age range $19-58$ years, $M=35.7$, SD $=10.8$ ).

\subsection{Materials}

Figures 1 and 2 show the material used for the original Corsi block test and the digital version. Figures 3 and 4 show the material used for the Stroop task test and its digital version.
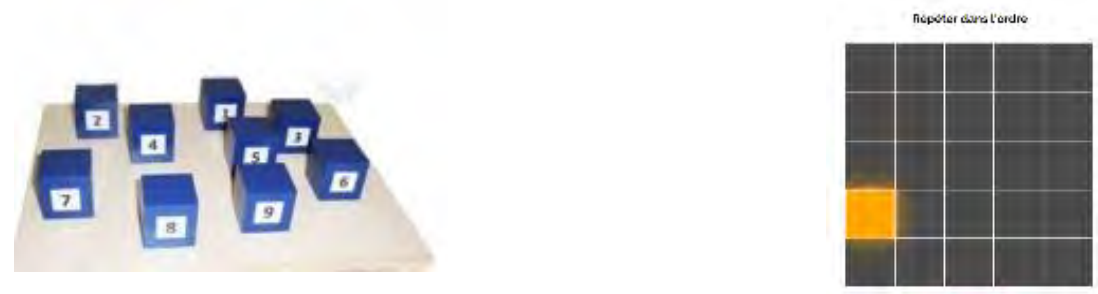
Figure 3. Original Stroop Task.

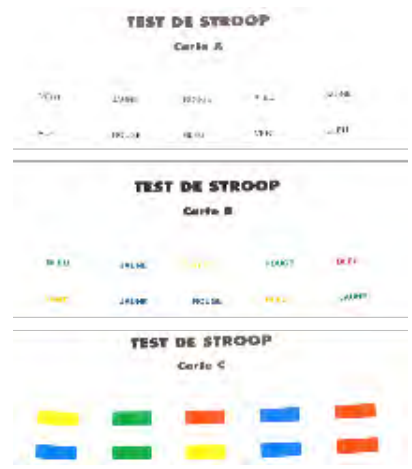

Figure 4. New Stroop.
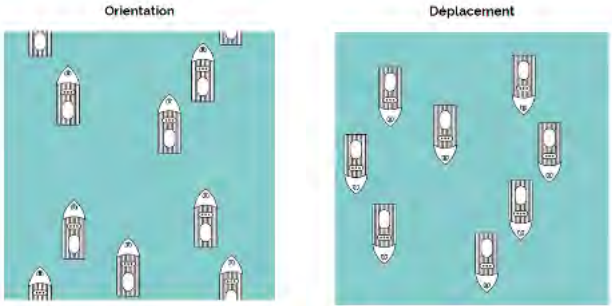

\subsection{Procedure}

All participants took the original tests in person, accompanied by an experimenter. The same participants were alone and at a distance to answer the digital creations of our tests (New Corsi and New Stroop).

\section{Face-to-face process}

Each test was conducted individually and lasted approximately 45 minutes. The experimentation was standardised, i.e., it was carried out exactly under the same conditions for each participant and followed the standardised procedures described in the manuals for each original test.

In the Corsi blocks task, the participant and the experimenter were seated opposite each other. The Corsi block board (see Figure 1) was in the middle of the table. The experimenter touched several blocks in succession in a pre-determined order. The participant had to memorise the series and then reproduce it. The test consisted of a first part with a recall of the sequence in order. In the second part, the sequence is recalled in reverse. The procedure and instructions used follow precisely those outlined in the study by Kessels, Van Zandvoort, Postma, Kappelle, and De Haan, (2000).

In the Stroop task, the test was carried out in four stages, with the participant and the experimenter positioned side by side. Three cards (see Figure 3.) were presented to respond to four tasks. A fixed time of 45 seconds was given to read or name the items on each card. The procedure and instructions used follow precisely those outlined in the study by Bayard, Erkes, and Moroni (2011).

\section{Remote process}

A link containing the tests to be taken remotely was sent by email to all the participants previously seen in the classroom. Participants were free to respond at their convenience. A welcome page presented the objective of the tests. Then, a training phase for each of the exercises was proposed. This phase allowed us to validate the correct understanding of the instructions.

For "New Corsi", the task was to reproduce from memory the sequences of cubes that lit up (in order and then in reverse order).

In "New Stroop", the boats on the screen moved and/or were oriented in a different direction each time (north, south, west, east). In the congruent situation, the direction of movement and orientation was similar, while in the incongruent situation the direction of movement and orientation was different. For 45 seconds the participant was asked to give the direction of movement $(\mathrm{M})$ or the direction of orientation $(\mathrm{O})$ of the boat in incongruent (i) and congruent (c) situations. In other words, the participant could encounter on the screen four cases of Mi Mc Oi Oc. 


\section{Results}

First and foremost, it is important to consider that "content validation, like other aspects of validity, is an ongoing process to which 'evidence' will be added over time" (Haynes, Richard, \& Kubany, 2005; as cited by Laveault, \& Grégoire, 2014).

All the cognitive tests constructed in digital version are based on tests and/or paradigms scientifically recognised in the literature.

To be able to compare the results, the raw scores were transformed into average percentages of success in the various tests. There is no gender effect on the percentages of success for any of the tests.

Table 1. Average percentage of test success.

\begin{tabular}{lcccc} 
& Original Corsi & New Corsi & Original Stroop & New Stroop \\
\hline $\mathrm{N}$ & 57 & 57 & 57 & 56 \\
Mean & 49.2 & 55.6 & 54.5 & 77.4 \\
Standard deviation & 6.59 & 11.1 & 16.6 & 30.4 \\
Minimum & 33.3 & 22.2 & 29 & 15.8 \\
Maximum & 66.7 & 77.8 & 100 & 100 \\
\hline
\end{tabular}

\subsection{Correlation matrix}

Table 2. Correlational matrix.

\begin{tabular}{llcccc} 
& & Original Corsi & New Corsi & Original Stroop & New Stroop \\
\hline \multirow{2}{*}{ Original Corsi } & Spearman's rho & -- & & \\
& p-value & -- & & \\
New Corsi & Spearman's rho & $0.335 *$ & -- & \\
& p-value & 0.011 & -- & \\
Original Stroop & Spearman's rho & $0.291 *$ & 0.153 & -- \\
& p-value & 0.028 & 0.255 & - \\
\multirow{2}{*}{ New Stroop } & Spearman's rho & $0.292 *$ & $0.424 * *$ & $0.272 *$ & - \\
& p-value & 0.029 & 0.001 & 0.043 & -- \\
\hline
\end{tabular}

Note. $\mathrm{p}<.05, * * \mathrm{p}<.01, * * * \mathrm{p}<.001$

Our results show moderate significant correlations (see Table 2.) between the original versions of the tests and our digital creations "New Corsi" and "New Stroop". Links are also found between the original Corsi block test and the original Stroop task as well as between the "New Corsi" and the "New Stroop". These results are consistent with existing links between memory and attentional abilities (cf. Maquestiaux, 2017).

The Mcdonald's $\varpi$ (1970) respective coefficients for "New Corsi" and "New Stroop" are also moderate with coefficients of 0.46 and 0.38 .

\section{Discussion}

The results we obtained should encourage us to continue our research efforts. Indeed, the significant links between the original Corsi block test and "New Corsi" as well as between the original Stroop task and "New Stroop" show that the two respective versions follow the same directions in the variation of scores. In other words, when scores increase in the original tests, they also increase in the created tests. Furthermore, the moderate positive correlations between the original Corsi blocks test and the original Stroop task test as well as between the "New Corsi" and the "New Stroop" are interesting since they highlight the very close link between working memory (WM) and attention since it allows to temporary 
keep information in mind (Maquestiaux, 2017). These elements are important to take into consideration in the validity of our creations. Finally, we believe that these moderate correlations are due to the relatively small sample of the study. We believe it is necessary to replicate a similar study on a larger scale.

From a practical point of view, a parallel survey was carried out to gather user feedback in the workplace. The aim was to ascertain the interest and attractiveness of our digital versions. The results, based on 3074 people, are very encouraging. Indeed, our creations obtained an average score of 3.6 for the pleasantness of the test and the design. In addition, 14.5\% of the 3074 people sent us a comment. These comments were categorised into four categories: positive, negative, neutral, and unclassifiable. The results are also encouraging and encourage us to continue our research and creation efforts, as $36.8 \%$ of the opinions were positive (compared to $34.5 \%$ for the neutral, $27.8 \%$ for the negative and $0.9 \%$ for the unclassifiable). In the workplace, these two new versions highlight the attention and memory skills of candidates, which should be enhanced during an interview focused on soft skills. Indeed, the greatest predictability is guaranteed by a method that necessarily combines cognitive assessments with other types of assessments, such as personality tests. Therefore, it is important to continue research efforts on the adaptation of digital cognitive tests in the workplace.

\section{References}

Alloway, T. P., \& Temple, K. J. (2007). A comparison of working memory skills and learning in children with developmental coordination disorder and moderate learning difficulties. Applied Cognitive Psychology, 21(4), 473-487.

Bayard, S., Erkes, J., \& Moroni, C. (2011). Victoria Stroop Test: normative data in a sample group of older people and the study of their clinical applications in the assessment of inhibition in Alzheimer's disease. Archives of Clinical Neuropsychology, 26(7), 653-661.

Chartier, P. (2009). The contribution of aptitude tests in recruitment: the example of the NV5-R. Psychologie du travail et des organisations, 15(2), 137-150.

Corsi, P. (1972). Memory and the medial temporal region of the brain. Unpublished doctoral dissertation), McGill University, Montreal, $Q B$.

Dégruel, M., Enlart, S., Le Boulaire, M., \&Marsaudon, S. (2011). The cognitive dimensions of work. Entreprise Personnelle, 296, 1-32.

Kessels, R. P., Van Zandvoort, M. J., Postma, A., Kappelle, L. J., \& De Haan, E. H. (2000). The Corsi block-tapping task: standardization and normative data. Applied neuropsychology, 7(4), 252-258.

Laveault, D., \& Grégoire, J. (2014). Introduction aux théories des tests en psychologie et en sciences de l'éducation. De Boeck.

Maquestiaux, F. (2017). Psychology of attention. De Boeck Supérieur.

McDonald, R. P. (1970). The theoretical foundations of principal factor analysis, canonical factor analysis and alpha factor analysis. British Journal of Mathematical Psychology,23, 1-21.

Ones, D. S., Dilchert, S., Viswesvaran, C., \& Salgado, J. F. (2010). Cognitive abilities. In J. L. Farr \& N. T. Tippins (Eds.), Handbook of employee selection (p. 255-275).

Salgado, J. F. (2017). Using ability tests in selection.

Schmidt, F. L., \& Hunter, J. E. (1998). The validity and utility of selection methods in personnel psychology: Practical and theoretical implications of 85 years of research findings. Psychological bulletin, 124(2), 262.

Schmidt, F. L., Oh, I. S., \& Shaffer, J. A. (2016). The Validity and Utility of Selection Methods in Personnel Psychology: Practical and Theoretical Implications of 100 Years... Fox School of Business Research Paper.

Sonnentag, S., Volmer, J., \& Spychala, A. (2008). Job performance. The Sage handbook of organizational behavior, 1, 427-447.

Terpstra, D. E., \& Rozell, E. J. (1997). Why some potentially effective staffing practices are seldom used. Public Personnel Management, 26(4), 483-495. 